painstaking efforts in geometry and surgery; compensation is often short of the diagrammatic textbook ideal. Subtrochanteric osteotomy remains the best hope of salvage when a badly distorted epiphysis has closed. Indeed it should be offered. The untreated patient with significant coxa vara may have little concern for some years; but premature degenerative change will surely follow, and the bizarre forms of osteoarthritis which are seen after past slipping of the upper femoral epiphysis are poor material for our present forms of hip surgery.

The conclusion is obvious. The best results and the simplest treatment follow early diagnosis. Vigilance cannot be overdone. Sometimes we are easily forewarned. Children with unilateral slipping are told to report any symptoms in the other leg. Dickensian fat boys, found lurking in hospital corridors, have been inveigled into an examination of their hips, and discovered with early 'slips'. The background is often much less suggestive, for in twelve-year-old children minor trauma and transient lower limb pains are not uncommon. But awareness may breed suspicion that a hip in this age group could be faulty, and such suspicion should be proved or disproved with full care.

\section{REFERENCES}

Burrcws, H. J. (1957): Slipped Upper Femoral Epiphysis, J. Bone Jt. Surg., 39, 641.

CAPENER, N. (1956): Reconstructive Surgery of the Hip Joint. In 'Modern Trends in Orthopaedics,' p. 4. 2nd Series, ed. Sir H. Platt. London: Butterworths.

DunN, D. M. (1964): The Treatment of Adolescent Slipping of the Upper Femoral Epiphysis, J. Bone Jt. Surg.. 46B, 621 .

HARRIS, W. R. (1950): The Endocrine Basis for Slipping of the Upper Femoral Epiphysis, J. Bone Jt. Surg., 32B, 5.

\title{
ACHALASIA OF THE CARDIA
}

\author{
Michael Bates, F.R.C.S. \\ Thoracic Surgeon, North Middlesex Hospital, London, N.18.
}

Achalasia of the cardia is a distressing condition which affects both sexes equally, and patients from childhood to old age. Achalasia is becoming increasingly recognised due to great improvements in the radiological techniques which demonstrate by cineradiography the complicated mechanism of swallowing and the disturbances which occur at the gastro-oesophageal junction. It is now universally accepted that achalasia is the correct term for this condition and the word cardiospasm is no longer used. However there is still considerable difference of opinion as to the best form of treatment and therefore this seems a suitable time to review the subject, particularly in relation to the complications, both of the untreated condition and also of the various treatments at present in use.

Adams and Trounce from Guy's Hospital wrote a classic article on this subject in 1961 when they went very extensively into the aetiology and pathology of the condition and analysed the results in 85 patients. They divide the condition into three clinical stages and in stage 1 there is often a history of sudden onset of marked dysphagia, frequent regurgitation and oesophageal pain. There may be an associated emotional disturbance although Flavell (1963) thinks this very unlikely particularly in children. The patient can become anaemic but little oesophageal dilatation occurs in the early stage. In stage 2 the oesophagus becomes markedly dilated and can hold a very considerable quantity of food and fluid. There is no pain and little regurgitation and any weight which has been lost in stage 1 is regained. An adequate quantity of food is forced through into the stomach purely by the weight of food which lies above it. After about 15 years the 3 rd stage of mega-oesophagus has developed with a sigmoid loop on the diaphragm, severe weight loss, hypertrophic pulmonary osteoarthropathy, polyarthritis and very occasionally death from starvation. Barrett (1964) does not believe that the disease necessarily passes through these three stages and has patients whom he has followed up for 30 years where the fusiform dilatation of stage 2 , or cucumber oesophagus as he calls it, remains static. Many cases, generally old people, are diagnosed with a short history and a megaoesophagus found on the first $\mathrm{X}$-ray.

The aetiology of this condition has never been convincingly explained although all writers are agreed that there is a degeneration or even congenital absence of ganglion cells in Auerbach's myenteric plexus in the oesophageal muscle wall. Whether this is a primary congenital absence or a secondary degeneration due to many years of food stagnation with fibrosis of the oesophageal wall is not at all clear. It is difficult to understand why a patient with congenital absence of ganglion cells in his oesophageal wall should not develop achalasia until old age, and so it may be that 
there are two quite different explanations for those who develop this condition either early or late in life. (Redo and Bauer, 1963). Cassella, Sayre, Brown and Ellis (1964) wrote an important paper on the aetiology when they re-investigated previous findings with the aid of the electron microscope. They found by this method that in only 19 out of 88 patients was there any degeneration of the ganglion cells in Auerbach's plexus. They also found a reduction in the number of cells in the dorsal motor nucleus of the vagus and Wallerian degeneration in the thoracic portion of every vagus nerve they examined by electron microscopy. This is an investigation not previously carried out and they believe the primary cause lies in one of these two findings.

It is generally agreed that there is an appreciably higher incidence of carcinoma of the oesophagus occurring in patients with achalasia than in the general population. In the Guy's Hospital series (Adams and others, 1961) 29\% of their cases developed a carcinoma, and Belsey (1963) reported nine carcinomas out of 94 cases of achalasia. These carcinomas are generally squamous cell in nature and situated in the mid-oesophagus. Belsey believes that the food stagnation produces a premalignant condition of the oesophagus in achalasia, while the reflux oesophagitis associated with a hiatus hernia does not do so, no carcinoma occurring in 500 cases of hiatus hernia which he had repaired.

Spontaneous rupture of the oesophagus in achalasia was reported for the first time by Benedict and Grillo in 1962, but it may be that this complication of achalasia occurs more often than is realised and Hill (1965) recently recorded two such cases, one occurring in late pregnancy. When the chest is opened to repair the oesophageal perforation, a Heller's operation must be performed at the same time for healing to occur.

Severe vomiting can also occur in the achalasic patient during late pregnancy and Bloomfield (1963) reported a case where Caesarian Section was necessary followed a week later by Heller's operation in order to stop this vomiting. Difficulty in diagnosis can arise in the 3rd stage of achalasia when the presenting symptoms are entirely pulmonary in nature. Spill-over lesions from the oesophagus produce solid areas of pneumonitis in the lung resembling a peripheral bronchial carcinoma. Barrett (1964) reports the presence of atypical mycobacteria which resemble acid-fast bacilli and are usually non-pathogenic, but when coated with oils such as liquid paraffin and butter or milk fats can produce lung lesions that simulate pulmonary tuberculosis.

\section{Treatment}

The best treatment for achalasia still seems to be undecided and in America the majority of writers favour bougienage and forceful pneumatic dilatation in the first instance and only recommend Heller's operation when these methods have failed.
(Benedict, 1964; Kurlander, Raskin, Kirsner and Palmer, 1963; Atkins and Tucker, 1964). Many of these patients have to undergo several dilatations and on each occasion they run the small risk of oesophageal rupture (Scott, 1964). In this country, however, repeated dilatations are not popular and Le Roux and Wright (1961) reviewed 55 patients from the Edinburgh Chest Unit treated between 1948-58 and found only 14 satisfactory results out of 28 cases treated by dilatations alone.

Fish and Harrison (1962) collected 474 cases of Heller's operation from the literature, 19401960 , and 419 of these had good results. Gahagan (1963) reported a large series of cases from the Henry Ford Hospital on 1963 all of whom had been treated with Heller's operation and without mortality. Howard, Wirts, Hopkins, Turk, Sicular, Cohen, Zimmerman, Wolf, Kark and Adkins, (1964), reported 58 out of 61 patients treated with transthoracic Heller's operation also without mortality. Some writers who are convinced that Heller's operation gives the best results for the treatment of this condition still prefer to perform the operation through the abdomen. They maintain that unsuspected abdominal disease such as pyloric obstruction will otherwise be missed and Frobese, Hawthorne and Nemir (1964) who reported 58 good results from 60 cases of transabdominal Heller's operation also performed pyloroplasty in 30 of them. While it is possible to perform Heller's operation satisfactorily through the abdomen in the early stage of this disease, it is technically impossible and even dangerous to attempt this route in the late stages with a sigmoid loop of oesophagus and peri-oesophagitis present in the mediastinum. Many of the indifferent results from Heller's operation have been due to a transabdominal approach and final success has only been achieved after a second thoracic operation.

The correct pre-operative preparation for a patient in the 3rd stage of achalasia is essential for a satisfactory result and this has been stressed by Belsey (1963). Oesophagoscopy must be performed in order to empty the oesophagus and make the anaesthetic safer, and also to exclude a carcinoma. A high protein liquid diet should be given and any anaemia, which may be very marked, should be corrected by transfusion. Pulmonary infections should also be treated before surgery is undertaken.

\section{Operation}

This is performed through a left lower thoracotomy and a single anterior incision is made through the longitudinal and circular muscle layers of the oesophageal wall for the full length of the narrowed segment of the oesophagus and this incision is carried upwards for $2 \mathrm{~cm}$. over the dilated lower end of the oesophagus and downwards for not more than $1 \mathrm{~cm}$. below the gastro-oesophageal junction. Great care must be taken that all the circular fibres are divided and 
also that the mucosal tube is not perforated. The vagi should not be damaged nor should the mechanism of the oesophageal hiatus. Allison (1964) considers that reflux after Heller's operation is a reflection on the technique and not on the myotomy itself. He found a hiatus hernia present in $6 \%$ of his cases, and only in these cases is it necessary to perform any plastic repair to the oesophageal hiatus.

The clinical results of Heller's operation performed through the chest are almost uniformly good although radiological reduction in the size of the oesophagus only occurs in about twothirds of the cases. Very occasionally pooling may occur even after a successful Heller's operation where a gross megaoesophagus and sigmoid loop are present. Howard and also Adams (1964) believe that oesophagectomy is justified in these cases. Even so Adams reports 3 deaths in 22 such operations.

In the present state of our knowledge there seems no doubt that the primary treatment of choice for achalasia of the cardia is a transthoracic Heller's operation.

\section{REFERENCES}

Adams, C. W. M., Brain, R. H. F., Ellis, F. G., KAUNTZE, R., and TROUNCE, J. R. (1961): Achalasia of the Cardia, Guy's Hosp. Rep., 110, 191.

AdAMS, H. D. (1964): Amyenteric Achalasis of the Oesophagus, Surg. Gynec. Obstet., 119, 251.

Allison, P. R. (1964): Function and Dysfunction of the Esophagus, Univ. Mich. med. Bull., 30, 102.

ATKINS, J. P., and TuCKER, J. A. (1964): Ächalasia, G.P. (Kansas), 30, 88.

BARRETT, N. R. (1964): Achalasia of the Cardia: Reflections upon a Clinical Study of Over 100 Cases, Brit. med. J., i, 1135.

BARRETT, N. R. (1964): Association of Esophageal and Pulmonary Diseases, Postgrad. Med., 36, 470.
Belsey, R. (1963): Functional Disease of the Oesophagus, Postgrad. med. J., 39, 290.

BENEDICT, E. B., and GRILLO, H. C. (1962): Spontaneous Rupture of Megaoesophagus in Achalasia, J. thorac. Cardio-vasc. Surg., 44, 272.

BENEDICT, E. B. (1964): Bougienage Forceful Dilation and Surgery in the Treatment of Achalasia. A Comparison of Results, J. Amer. med. Ass., 188, 355.

Bloomfield, R. D. (1963): Pregnancy and Achalasia, Amer. J. Obstet. Gynaec., 86, 1074.

Cassella, R. R., Brown, A. L., Sayre, G. P., and Ellis, F. H. (1964): Achalasia of the Esophagus, with Pathologic and Etiologic Considerations, Ann. Surg., 160, 474.

Flavell, G. (1963): The Oesophagus, London: Butterworth.

FISH, J., and Harrison, A. W. (1962): Achalasia of the Oesophagus: A Review, Amer. Surg., 28, 545.

Frobese, A. S., Hawthorne, H. R., and Nemir, P. (1964): Reflections on the Surgical Management of Achalasia of the Oesophagus, Amer. J. Surg., 107, 249.

GaHAGAN, T. (1963): The Surgical Treatment of Cardiospasm, Illinois, med. J., 124, 331 .

Hill, I. M. (1965): Personal Communication.

Howard, J. T., WIRTS, C. W., Hopkins, W. A., TURK, L. N., SICUlaR, A., COHEN, B. R., ZIMMERMAN, A.,, WOLF, B. S., KARK, A. E., and ADKINS, P. C. (1964): Symposium on theo Oesophagus, Amer. J. Gastroent., 41, 587.

Le RouX, B. T., and Wright, J. T. (1961): Cardiospasm, Brit. J. Surg., 48, 619.

KURLANDER, D. J., RASKIN, H. F., KIRSNER, J. B. and PALMER, W. L. (1963): Therapeutic Value of the Pneumatic Dilator in Achalasia of the Esophagus. Long Term Results in 62 Living Patients, Gastroenterology, 45, 604.

Redo, S. F., and BAUER, C. H. (1963): Management of Achalasia in Infancy and Childhood, Surgery, $53,263$.

ScoTt, N. M. JR. (1964): Achalasia of the Oesophagus, Med. Ann. D.C., 33, 202. 